\title{
Evaluation of Local and Multinational Maize Hybrids for Tolerance Against High Temperature using Stress Tolerance Indices
}

\author{
Saleem Ur Rahman ${ }^{1}$, Muhammad Irfan Yousaf ${ }^{*}$, Mozammil Hussain ${ }^{2}$, Khadim Hussain ${ }^{1}$, Shahid \\ Hussain ${ }^{1}$, Muhammad Husnain Bhatti ${ }^{1}$, Dilbar Hussain ${ }^{1}$, Aamir Ghani ${ }^{1}$, Abdul Razaq ${ }^{1}$, Muhammad \\ Akram ${ }^{1}$, Iqra Ibrar', Muhammad Shakeel Ahmad", Shoaib Anwar Kohli ${ }^{3}$, Muhammad Abubakar Siddiq ${ }^{4}$
}

\author{
${ }^{1}$ Maize and Millets Research Institute (MMRI), Yusafwala, Sahiwal, Pakistan; ${ }^{2}$ Pakistan Agricultural Research \\ Council, Pakistan; ${ }^{3}$ Fodder Research Institute, Sargodha, Pakistan; ${ }^{4}$ Soil and Water testing laboratory for research, \\ Sargodha, Pakistan.
}

\begin{abstract}
The current study was conducted to evaluate maize hybrids for their high temperature tolerance ability based on their performance as assessed through different high temperature stress indices. Nine maize hybrids were screened under optimal and high temperature stress conditions (late sowing) for three consecutive spring seasons (Spring 2017-18, 2018-19 and 2019-20), laid out under split-split-plot design under RCBD. Results reveled significant differences among stress indices for all three seasons and both conditions. Correlation analysis indicated that some high temperature stress indices i.e., STI, MP, GMP and HARM had a strong positive correlation with kernel yield under normal (Yp) and high temperature stress conditions (Ys). Biplot analysis further unveiled that two local maize hybrids i.e., YH5507 and YH-5427 were the most productive, stable and heat tolerant while YH-5532, P-1543 and NK-8711 showed poor performance under high temperature stress conditions as compared to normal sowing. High temperature stress indices could be efficiently used to screen heat tolerant genotypes. Received | March 10, 2021; Accepted | October 12, 2021; Published | January 20,2022

*Correspondence | Muhammad Irfan Yousaf, Maize and Millets Research Institute (MMRI), Yusafwala, Sahiwal, Pakistan; Email: irfanpbg. uaf@gmail.com

Citation | Rahman, S.U., M.I. Yousaf, M. Hussain, K. Hussain, S. Hussain, M.H. Bhatti, D. Hussain, A. Ghani, A. Razaq, M. Akram, I. Ibrar, M.S. Ahmad, S.A. Kohli, M.A. Siddiq. 2022. Evaluation of local and multinational maize hybrids for tolerance against high temperature using stress tolerance indices. Pakistan Journal of Agricultural Research, 35(1): 36-46.

DOI | https://dx.doi.org/10.17582/journal.pjar/2022/35.1.36.46

Keywords | Climate change, Selection, Screening, Biplot analysis, Heat stress
\end{abstract}

\section{Introduction}

$\mathrm{H}$ eat stress as a result of high ambient temperature is the one of the most alarming threat to crop production in Pakistan as well as Worldwide. It becomes more severe in spring crop during reproductive stage i.e., anthesis and grain development stages when high ambient temperature coincides with these stages (Ghani et al., 2017; Yousaf et al., 2018; 2019; Riaz et al., 2021). The normal temperature required for reproductive growth of maize crop ranges from $26^{\circ} \mathrm{C}$ to $31^{\circ} \mathrm{C}$ (Sánchez et al., 2014). Crop exposure to higher temperature $\left(>35^{\circ} \mathrm{C}\right)$ could significantly reduce maize kernel yield as reported by many researchers (Thornton et al., 2010; Lobell et al., 2011; Deryng et al., 2011; Ghani et al., 2020). Brown (2009) in a global study, reported a $10 \%$ reduction in kernel yield for every $1^{\circ} \mathrm{C}$ above normal temperature $\left(29^{\circ} \mathrm{C}\right)$. It is also predicted that $8.1 \%$ reduction in kernel yield is expected in Pakistan by 2055 (Iqbal et al., 2011) due to clanging climatic conditions. These studies show that there is an utmost need for the selection March 2022 | Volume 35 | Issue 1 | Page 36 
and development of heat tolerant maize hybrids to cope with deleterious effects of climate change especially high temperature.

High temperature stress could be very fetal to anthesis and grain development stages in maize as a single, severely hot day (above $43^{\circ} \mathrm{C}$ ) could severely reduce kernel yield. Furthermore, high temperature during reproductive stage could also reduce seed setting (51\% to $81 \%)$, number of kernels per ear, thousand grain weight, pollen viability, silk receptivity, assimilation rate and net photosynthetic rate which ultimate decrease kernel yield (Traore et al., 2000; Wahid et al., 2007; Yousaf et al., 2017; Fonseca et al., 2005). The flowering stage in maize - more specifically, anthesis and silking - are more heat sensitive than the grain filling stage, so high temperature stress during the former stages can result in greater reductions in grain yield (Zhang et al., 2013). Therefore, improvement of maize hybrids for thermotolerance is one of the most challenge for maize breeders. Selection of maize germplasm for the identification of heat tolerance parents/genotypes is the prerequisite for the development of heat resilient maize hybrids (Abu-Romman, 2016). The most common method for the selection of germplasm is by growing breeding material under optimal and stress conditions and then selecting the lines/genotypes with higher kernel yield (Ehlers and Hall, 1998). Hence, it is pivotal to screen maize hybrids under optimal and stress conditions.

For efficient selection of genotypes under high temperature, several stress related indices have been developed. Among these, STI (Stress Tolerance Index), SSI (Stress Susceptibility Index), Stress Tolerance (TOL), MP (Mean productivity index), GMP (Geometric mean productivity index), HARM (Harmonic mean productivity), GOL (Golden mean), YI (Yield index) and YSI (Yield stability index) (Khalili et al., 2012; Grzesiak et al., 2019; Zhao et al., 2019). These stress indices are based on either stress tolerance or susceptibility of hybrids (Fernandez, 1992). The best selection criteria should identify and discriminate genotypes that have uniform superiority under normal and high temperature stress conditions from those genotypes which are productive under one condition only. TOL could be effectively use to select maize hybrids with high yield potential under high temperature stress conditions. But this criterion does not permit to differentiate between high yielding maize hybrids under high temperature stress condi- tions from the best performing hybrids under both conditions. Barutcular et al. (2016) showed that the genotypes having higher values for SSI and TOL are considered as stress susceptible genotypes and therefore, only suitable for sowing in optimal conditions. Sedri et al. (2019) reported that the best index for the selection of maize hybrid under stress conditions must comprised of STI. Many researchers suggested a combination of different stress indices, having significantly positive association with kernel yield under normal and stress conditions, should be utilized to screen genotypes under stress conditions (Grzesiak et al., 2019; Zhao et al., 2019). The purpose of current investigation was to screen maize hybrids for their heat tolerance, so that most appropriate hybrids can be recommended for sowing in heat prone areas of Pakistan.

\section{Materials and Methods}

\section{Experimental material and site}

The test material used in the study was comprised of nine (09) maize hybrids including six (06) local i.e., YH-5427, YH-5482, YH-5213, YH-5532, YH-5507 and $\mathrm{YH}-1898$ and three (03) multinational hybrids i.e., P-1543, DK-6724 and NK-8711 of well-known companies i.e., Cortiva, Bayer and Syngenta, respectively. Among local hybrids, YH-1898 and $\mathrm{YH}-5427$ were the approved hybrids for general cultivation in all over Punjab province while other four maize hybrids i.e., YH-5482, YH-5213, YH-5532 and YH-5507 were the elite maize hybrids that are in the process of evaluation. All these hybrids were assessed under optimal and high temperature stress conditions for three consecutive spring seasons i.e., 2017-18, 2018-19 and 2019-20, respectively at Maize and Millets Research Institute (MMRI), Yusafwala-Sahiwal, Pakistan.

\section{Experimental design and layout}

Nine (09) maize hybrids we cultivated using RCBD with three replicates for three consecutive spring seasons (2017-18, 2018-19 and 2019-20). For each season, sowing was done on two different dates; first set of hybrids was sown as normal sowing in $2^{\text {nd }}$ week of February and second set of same hybrids was sown on $3^{\text {rd }}$ week of March as late sowing (high temperature stress conditions). In late sowing (high temperature stress) conditions, reproductive stage of crop coincides with high temperature $\left(>40{ }^{\circ} \mathrm{C}\right)$, which was significantly higher from optimum temperature $\left(32-34^{\circ} \mathrm{C}\right)$ required for fertilization, seed setting and 
kernel yield. For every testing season, experimental design, genetic material, replications and sowing dates were same. Each entry/hybrid was sown in 12 $\mathrm{m}^{2}$ sized plot, having $15 \mathrm{~cm}$ plant to plant and $75 \mathrm{~cm}$ row-to-row distance, respectively. Two seed per hill were planted with the help of dibbler and seedling stage, thinned to single seedling per hill to ensure optimum plant population per hectare. For proper crop growth and development, $270 \mathrm{~kg} / \mathrm{ha}$ nitrogen, 110 $\mathrm{kg} / \mathrm{ha}$ phosphorus and $60 \mathrm{~kg} / \mathrm{ha}$ potash were applied under both normal and high temperature stress conditions, respectively. Other agronomic/management practices like application of pre-emergence herbicides and use of pesticide was carried out to insure proper plant health.

\section{Data recording}

Data was recorded for several morphological, phenological, physiological and kernel quality traits for all hybrids. Kernels per ears (NE) and 1000 kernel weight (TKW) were recorded after harvesting of entries and drying in sunlight to insure 15\% kernel moisture. Net photosynthetic rate $(\mathrm{Pn})$ was measured through Infrared Gas Analyzer (IRGA), using a handheld photosynthetic system CI-340. The data was recorded during the grain development in 10 random ear leaves per hybrid between 10:00 am and 12:00 am. Kernel quality analysis was accomplished by near infrared spectrometry (NIR-Inframatic 9200, Parten Instruments, Sweden) to measure kernel protein content percentage (Pro) and kernel oil content percentage (Oil). Grain yield (Kg/hectare) was calculated through the following formula as described by Tandzi and Mutengwa (2020);

Grain Yield (Kg ha - 1)

$=\frac{\text { Fresh ear weight }(\mathrm{Kg} / \mathrm{plot}) \times(100-\text { Moisture Contents }) \times 0.8}{(100-15) \times \text { Area Harvested } / \text { plot }} \times 10000$

\section{Determination of Stress Indices}

High temperature stress indices were calculated from kernel yield of normal ( $\mathrm{Y} p$ ) and high temperature stress conditions (Ys) as used by Grzesiak et al. (2019) and Zhao et al. (2019).

Stress Tolerance Index $(\mathrm{STI})=(\mathrm{Y} s \times \mathrm{Y} p) /(\mathrm{Y} p) 2$

Stress Susceptibility Index $(\mathrm{SSI})=2(\mathrm{Y} s \times \mathrm{Y} p) /(\mathrm{Y} p+\mathrm{Y} s)$

Stress Tolerance $(\mathrm{TOL})=\mathrm{Y} p-\mathrm{Y}_{s}$

Mean productivity index $(\mathrm{MP})=(\mathrm{Y} p+\mathrm{Y} s) / 2$

Geometric mean productivity index $(\mathrm{GMP})=\sqrt{\mathrm{Y} p+\mathrm{Y} s}$

Harmonic mean productivity index $(\mathrm{HARM})=2(\mathrm{Y} s$ $\times \mathrm{Y} p) /(\mathrm{Y} p+\mathrm{Y} s)$

Golden mean $(\mathrm{GOL})=[1-(\mathrm{Y} s / \mathrm{Y} p)] /[1-(\mathrm{Y} s / \mathrm{Y} p)]$
Yield index $(\mathrm{YI})=\mathrm{Y} s / \mathrm{Y} \underline{\mathrm{s}}$

Yield stability index $(\mathrm{YSI})=\mathrm{Y} s / \mathrm{Yp}$

Where;

Y $p=$ Normal Kernel yield under normal conditions

Ys $=$ Kernel yield under high temperature stress conditions

\section{Data analysis}

The data was subjected for statistical analysis using Statistix 8.1 and XLSTAT 16.0 statistical packages. Analysis of variance and correlation coefficient analysis was executed according to Steel et al. (1997). Furthermore, first two principal components (PCs) were used to plot different biplots based on the high temperature stress indices under optimal and stress conditions for three successive Spring seasons (Sneath and Sokal, 1973). Microsoft Excel (Version 2019) was also utilized for the presentation of data in graphical form.

\section{Metrological Conditions during the trial}

The research trials were conducted in three consecutive spring seasons i.e., 2017-18, 2018-19 and 201920. For all these sowing seasons, normal set of hybrids was sown in the mid of February and harvested in the month of May-June. However, late sown set (High temperature stress) maize hybrids were planted in mid of March while harvested in the month of July. For each season, lowest day and night temperatures were recorded in the month of February while highest average day and night temperature were recorded in the month of June and July, which coincided with the flowering and grain development stages of maize crop. Under normal sowing, average minimum temperature remained $18.9^{\circ} \mathrm{C}$ while average maximum temperature was recorded as $35.7{ }^{\circ} \mathrm{C}$. However, an increase of about $4{ }^{\circ} \mathrm{C}$ was observed in both average minimum $\left(22.5^{\circ} \mathrm{C}\right)$ and maximum $\left(39.1^{\circ} \mathrm{C}\right)$ temperature in late sown (high temperature stress) conditions (Figure 1). The average maximum temperature during reproductive stage under high temperature stress conditions was recorded $41.7{ }^{\circ} \mathrm{C}$ which was detrimental to pollen viability, fertilization, seed setting and ultimately kernel yield in maize.

\section{Results and Discussion}

\section{Analysis of Variance (ANOVA)}

Results obtained from combined ANOVA unveiled the presence of significant $(\mathrm{P}<0.01)$ differencebetween 


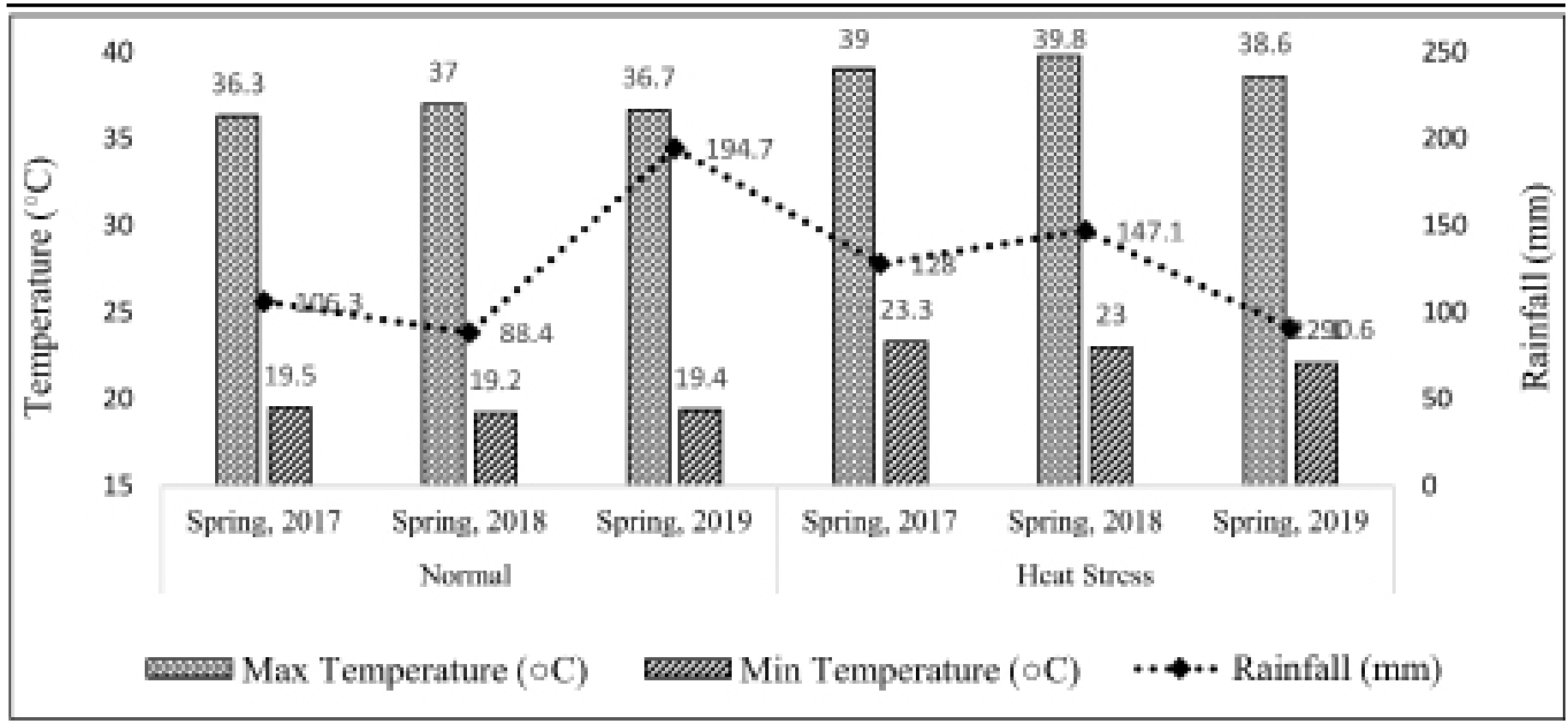

Figure 1: Three Years Metrological data of normal and heat sown maize hybrids.

Table 1: Analysis of variance for kernel yield and quality related traits in maize hybrids for three spring seasons (2017, 2018 and 2019).

$\begin{array}{llllllll}\text { SOV } & \text { DF } & \text { KE } & \text { TKW } & \text { Pn } & \text { Pro } & \text { Oil } & \text { GY } \\ \text { Replications } & 2 & 18.9 & 5.2 & 2.30 & 0.1896 & 0.00296 & 29821.5 \\ \text { Hybrids } & 8 & 57414.1^{* *} & 7552.6^{* *} & 153.88^{* *} & 20.6125^{* *} & 4.0275^{* *} & 10860000^{* *} \\ \text { Years } & 2 & 3788.6^{* *} & 7214^{* *} & 241.40^{* *} & 0.5817^{* *} & 0.2066^{* *} & 25950000^{* *} \\ \text { Treatment } & 1 & 99062^{* *} & 11960.9^{* *} & 1009.50^{* *} & 1.8689^{* *} & 1.1755^{* *} & 110400000^{* \prime} \\ \text { Hybrid*Year } & 16 & 8544.8^{* *} & 476.7^{* *} & 22.83^{* *} & 0.1098^{\mathrm{NS}} & 0.0591^{*} & 2030920^{* *} \\ \text { Hybrid*Treatment } & 8 & 3724.7^{* *} & 558.5^{* *} & 80.40^{* *} & 0.1239^{\mathrm{NS}} & 0.0180^{\mathrm{NS}} & 2631676^{* \prime} \\ \text { Year*Treatment } & 2 & 12005.8^{* *} & 7472.9^{* *} & 274.61^{* *} & 0.7772^{* *} & 0.0155^{\mathrm{NS}} & 6609754^{* *}\end{array}$

Significant changes are highlighted by an asterisk $\left({ }^{*}\right) ;{ }^{*} P \leq 0.05,{ }^{* *} P \leq 0.01 ;$ ns: non-significant; KE: Kernels per ear; TKW: Thousand Kernel Weight (g); Pn: Net Photosynthetic Rate ( $\mu$ mole $\mathrm{m}^{-2} \mathrm{~s}^{-1}$ ); Pro: Kernel Protein Content percentage (\%); Oil: Kernel Oil Content percentage (\%); GY: Grain Yield per hater $\left(\mathrm{kg} \mathrm{ha}^{-1}\right)$

maize hybrids for kernel yield and associated parameters under normal and stress conditions (Table 1). A high genetic divergence among maize hybrids was observed that allow suitable hybrids selection under normal and high temperature stress conditions. Similar results were reported by Saeed et al. (2018), Yousaf et al. (2018) and Shehzad et al. 2019, which revealed the presence of significant variations among maize hybrids under high temperature stress conditions. Among nine maize hybrids, two local maize hybrids YH-5507 and YH-5427 produced high kernel yield under both normal and high temperature stress conditions (Figure 2). NK-8711, P-1543 and DK-6724 had higher kernel yield under normal sowing conditions, but produce lower kernel yield under high temperature stress conditions. However, the interaction between hybrids and treatments (sowing conditions) for quality traits i.e., kernel protein content percent- age and kernel oil content percentage were non-significant. Similarly, Hybrid vs Year interaction for kernel protein content percentage and Year vs Treatment interaction for kernel oil content percentage were also non-significant. Yousaf et al. (2018) and Khalid et al. (2020) also reported the significance of locally developed maize hybrids for high temperature stress tolerance and showed that maize hybrids developed from heat tolerant/adaptive inbred lines were comparatively more productive than imported, exotic hybrids under high temperature stress conditions.

Correlation coefficient analysis for the nine stress indices and kernel yield under normal and high temperature stress conditions in nine maize bybrids

Selection for the best and most effective stress related indices as the selection criterion to discriminate desirable hybrids was determined through correlation March 2022 | Volume 35 | Issue 1 | Page 39 


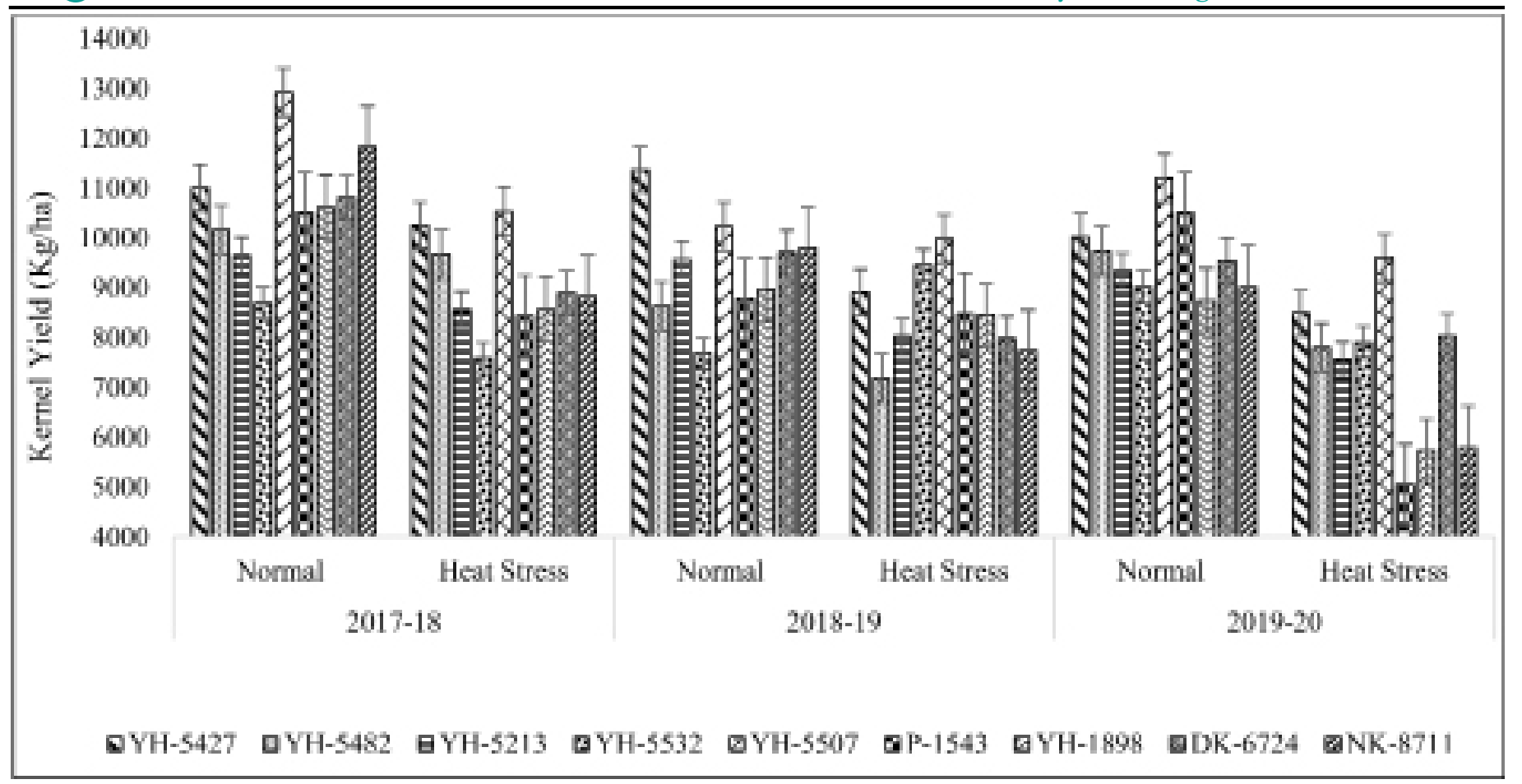

Figure 2: Three year's averages of kernel yield of corn hybrids under normal and high temperature stress conditions.

coefficients analysis between nine different stress tolerance indices of kernel yield under normal $(Y p)$ and high temperature stress conditions $(Y s)$ for three spring seasons (Table 2). Correlation coefficient analysis revealed that $Y p$ had a significantly positive correlation with STI $\left(0.934^{*}, 0.794^{*}\right.$ and 0.664$)$, MP (0.947, 0.802 and 0.725), GMP $\left(0.936^{*}, 0.792^{*}\right.$ and $0.639)$ and HARM $\left(0.924^{*}, 0.781^{*}\right.$ and 0.565$)$ for three spring seasons, 2017-18, 2018-19 and 2019-20, respectively (Table 2). Similarly, Ys was found to be positively related to STI $\left(0.921^{*}, 0.697^{*}\right.$ and $\left.0.955^{*}\right)$, $\operatorname{MP}\left(0.910^{*}, 0.689^{*}\right.$ and $\left.0.930^{*}\right), \operatorname{GMP}\left(0.923^{*}, 0.700^{*}\right.$ and $\left.967^{*}\right)$, HARM $\left(0.935^{*}, 0.710^{*}\right.$ and $\left.0.967^{*}\right)$ and YI (1.000*, 1.000* and 1.000*) (Table 2). Four stress indices i.e. STI, MP, GMP and HARM proved their worth in identification of superior and productive hybrids under optimal and stress conditions. These indices were the most appropriate indices for the selection of highly productive and stress tolerant maize hybrids because of their significant positive correlation with kernel yield. Similar findings were also described by Khodarahmpour et al. (2011) and Moradi et al. (2012) in maize. Kamrani et al. (2018) suggested that high yielding and heat tolerant hybrids could be designated on the basis of STI, MP, GMP and HARMS.

It was also observed that correlation between $\mathrm{Yp}$ and Ys was also positive for under all three seasons but was significant only under spring-2017 suggesting that high yielding maize hybrids could be selected on the basis of their kernel yield under both conditions as shown by Zhao et al. (2019). It further suggested that indirect selection of heat tolerant maize hybrids could be done in accordance with the results found under normal condition. Aghaei-Sarbarze et al. (2009) also showed hybrids with higher kernel yield also had good heat tolerance under stress condition.

\section{Phenotypes for the nine stress tolerance indices and kernel yield under normal and high temperature stress condi- tions in nine maize bybrids}

Kernel yield was used to calculate heat tolerance indices in nine maize hybrids under normal and high temperature stress (Table 3). Maize hybrids i.e., NK-8711, P-1543 and YH-1898 had highest value for TOL and SSI in three seasons especially in Spring-2017 and Spring-2019, respectively. All these hybrids had high kernel yield under normal condition while low yields under high temperature stress and thus, were selected as stress susceptible hybrids. The average lowermost value of tolerance index for three seasons was observed in YH-5482 and YH-5532, which depict their lower yield under both conditions due to low differences in their kernel yield under both conditions. Similar findings were reported by Khodarahmpour et al. (2011) and Zhao et al. (2019) who showed a strong negative correlation of TOL with Ys. It is reported that low TOL value is correlated with lower susceptibility to high temperature stress and selection based on TOL will potentially lead to the 
Table 2: Correlation between different stress indices in corn bybrids for three consecutive spring seasons (Spring 2017, 2018 and 2019).

\begin{tabular}{|c|c|c|c|c|c|c|c|c|c|c|c|}
\hline Variables & & STI & SSI & TOL & MP & GMP & HARM & GOL & YSI & YI & Yp \\
\hline \multirow[t]{3}{*}{ SSI } & $r_{2017}$ & 0.119 & & & & & & & & & \\
\hline & $r_{2018}$ & 0.112 & & & & & & & & & \\
\hline & $r_{2019}$ & -0.753 & & & & & & & & & \\
\hline \multirow[t]{3}{*}{ TOL } & $r_{2017}$ & 0.319 & 0.978 & & & & & & & & \\
\hline & $r_{2018}$ & 0.180 & 0.990 & & & & & & & & \\
\hline & $r_{2019}$ & -0.658 & 0.987 & & & & & & & & \\
\hline \multirow[t]{3}{*}{ MP } & $r_{2017}$ & 0.997 & 0.152 & 0.350 & & & & & & & \\
\hline & $r_{2018}$ & 0.999 & 0.120 & 0.192 & & & & & & & \\
\hline & $r_{2019}$ & 0.994 & -0.704 & -0.596 & & & & & & & \\
\hline \multirow[t]{3}{*}{ GMP } & $r_{2017}$ & 0.998 & 0.121 & 0.320 & 0.999 & & & & & & \\
\hline & $r_{2018}$ & 0.999 & 0.108 & 0.176 & 0.999 & & & & & & \\
\hline & $r_{2019}$ & 0.998 & -0.781 & -0.686 & 0.993 & & & & & & \\
\hline \multirow[t]{3}{*}{ HARM } & $r_{2017}$ & 0.998 & 0.090 & 0.289 & 0.998 & 0.999 & & & & & \\
\hline & $r_{2018}$ & 0.999 & 0.096 & 0.160 & 0.997 & 0.999 & & & & & \\
\hline & $r_{2019}$ & 0.991 & -0.833 & -0.749 & 0.977 & 0.996 & & & & & \\
\hline \multirow[t]{3}{*}{ GOL } & $r_{2017}$ & 0.029 & -0.910 & -0.850 & 0.015 & 0.041 & 0.068 & & & & \\
\hline & $r_{2018}$ & 0.436 & -0.061 & -0.132 & 0.402 & 0.433 & 0.463 & & & & \\
\hline & $r_{2019}$ & 0.773 & -0.938 & -0.891 & 0.746 & 0.798 & 0.831 & & & & \\
\hline \multirow[t]{3}{*}{ YSI } & $r_{2017}$ & -0.119 & -1.000 & -0.978 & -0.152 & -0.121 & -0.090 & 0.910 & & & \\
\hline & $r_{2018}$ & -0.112 & -1.000 & -0.990 & -0.120 & -0.108 & -0.096 & 0.061 & & & \\
\hline & $r_{2019}$ & 0.753 & -1.000 & -0.987 & 0.704 & 0.781 & 0.833 & 0.938 & & & \\
\hline \multirow[t]{3}{*}{ YI } & $r_{2017}$ & 0.921 & -0.270 & -0.070 & 0.910 & 0.923 & 0.935 & 0.392 & 0.270 & & \\
\hline & $r_{2018}$ & 0.697 & -0.631 & -0.579 & 0.689 & 0.700 & 0.710 & 0.431 & 0.631 & & \\
\hline & $r_{2019}$ & 0.955 & -0.914 & -0.849 & 0.930 & 0.967 & 0.986 & 0.898 & 0.914 & & \\
\hline \multirow[t]{3}{*}{ Yn } & $r_{2017}$ & 0.934 & 0.462 & 0.632 & 0.947 & 0.936 & 0.924 & -0.280 & -0.462 & 0.729 & \\
\hline & $r_{2018}$ & 0.794 & 0.685 & 0.740 & 0.802 & 0.792 & 0.781 & 0.195 & -0.685 & 0.120 & \\
\hline & $r_{2019}$ & 0.664 & -0.024 & 0.121 & 0.725 & 0.639 & 0.565 & 0.158 & 0.024 & 0.422 & \\
\hline \multirow[t]{3}{*}{ Ys } & $r_{2017}$ & 0.921 & -0.270 & -0.070 & 0.910 & 0.923 & 0.935 & 0.392 & 0.270 & 1.000 & 0.729 \\
\hline & $r_{2018}$ & 0.697 & -0.631 & -0.579 & 0.689 & 0.700 & 0.710 & 0.431 & 0.631 & 1.000 & 0.120 \\
\hline & $r_{2019}$ & 0.955 & -0.914 & -0.849 & 0.930 & 0.967 & 0.986 & 0.898 & 0.914 & 1.000 & 0.422 \\
\hline
\end{tabular}

Significant Correlation values are bighlighted as Bold at P $\leq 0.05$, STI: Stress Tolerance Index; SSI: Stress Susceptibility Index; TOL: Stress Tolerance; MP: Mean productivity index; GMP: Geometric mean productivity index; HARM: Harmonic mean productivity index; GOL: Golden mean; YI: Yield index; YSI: Yield stability index, Yp: Kernel yield under normal conditions; Ys: Kernel yield under high temperature stress conditions

development of highly productive genotypes under high temperature stress conditions (Rosielle and Hamblin, 1981). According to STI, two local maize hybrids $\mathrm{YH}-5507$ and $\mathrm{YH}-5427$ were revealed as heat tolerant hybrids and produced highest kernel yields under both conditions. Therefore, STI was able to identify high yielding maize hybrids under high temperature stress conditions. As SSI characterize maize hybrids as heat resilient according to the higher kernel yield under both conditions while TOL characterize maize hybrids as heat tolerant on the basis of lower kernel yield under both sowing conditions. Therefore, it is better to select heat tolerant maize hybrids according to STI rather than TOL. Similar findings were obtained by Zhao et al. (2019) who revealed that STI is better index to identify heat tolerant maize hybrids rather than TOL.

The maximum values of MP, GMP and HARM were observed for YH-5507,YH-5427 and DK-6724. These hybrids were identified as the most stable and stress tolerant hybrids under both conditions. Moreover, 
Table 3: Values of different stress indices in corn bybrids for three consecutive spring seasons (Spring 2017, 2018 and 2019).

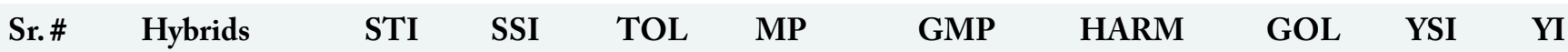

Mean values for different high temperature stress indices (Spring, 2017-18)

$\begin{array}{lllllllllll}1 & \text { YH-5427 } & 0.99 & 0.44 & 747 & 10630 & 10623 & 10616 & 28.5 & 0.93 & 1.13 \\ 2 & \text { YH-5482 } & 0.86 & 0.31 & 494 & 9925 & 9922 & 9919 & 40.2 & 0.95 & 1.07 \\ 3 & \text { YH-5213 } & 0.72 & 0.73 & 1089 & 9109 & 9092 & 9076 & 16.7 & 0.89 & 0.95 \\ 4 & \text { YH-5532 } & 0.58 & 0.82 & 1106 & 8142 & 8123 & 8104 & 14.7 & 0.87 & 0.84 \\ 5 & \text { YH-5507 } & 1.19 & 1.20 & 2389 & 11730 & 11669 & 11608 & 9.8 & 0.82 & 1.17 \\ 6 & \text { P-1543 } & 0.78 & 1.28 & 2078 & 9474 & 9417 & 9360 & 9.1 & 0.80 & 0.93 \\ 7 & \text { YH-1898 } & 0.80 & 1.25 & 2045 & 9602 & 9547 & 9493 & 9.4 & 0.81 & 0.95 \\ 8 & \text { DK-6724 } & 0.84 & 1.15 & 1921 & 9858 & 9811 & 9764 & 10.3 & 0.82 & 0.98 \\ 9 & \text { NK-8711 } & 0.91 & 1.64 & 3001 & 10330 & 10221 & 10112 & 6.9 & 0.75 & 0.98\end{array}$

Mean values for different high temperature stress indices (Spring, 2018-19)

$\begin{array}{lllllllllll}1 & \text { YH-5427 } & 1.14 & 2.15 & 2465 & 10139 & 10063 & 9989 & 8.2 & 0.78 & 1.05 \\ 2 & \text { YH-5482 } & 0.70 & 1.67 & 1456 & 7909 & 7875 & 7842 & 10.9 & 0.83 & 0.85 \\ 3 & \text { YH-5213 } & 0.87 & 1.60 & 1551 & 8799 & 8764 & 8730 & 11.3 & 0.84 & 0.95 \\ 4 & \text { YH-5532 } & 0.82 & 2.29 & 1776 & 8572 & 8526 & 8480 & 9.7 & 1.23 & 1.12 \\ 5 & \text { YH-5507 } & 1.15 & 0.24 & 852 & 10108 & 10107 & 10106 & 80.2 & 0.98 & 1.18 \\ 6 & \text { P-1543 } & 0.84 & 0.35 & 607 & 8629 & 8627 & 8626 & 56.2 & 0.97 & 1.00 \\ 7 & \text { YH-1898 } & 0.85 & 0.57 & 918 & 8709 & 8705 & 8701 & 33.6 & 0.94 & 1.00 \\ 8 & \text { DK-6724 } & 0.87 & 1.76 & 1730 & 8847 & 8805 & 8762 & 10.2 & 0.82 & 0.94 \\ 9 & \text { NK-8711 } & 0.86 & 2.08 & 2062 & 8771 & 8710 & 8650 & 8.5 & 0.79 & 0.91 \\ \text { Mean values for different high temperature stress indices (Spring, 2019-20) } & & & & \\ 1 & \text { YH-5427 } & 0.91 & 0.63 & 1527 & 9265 & 9233 & 9202 & 12.1 & 0.85 & 1.16 \\ 2 & \text { YH-5482 } & 0.81 & 0.82 & 1945 & 8765 & 8710 & 8657 & 9.0 & 0.80 & 1.06 \\ 3 & \text { YH-5213 } & 0.75 & 0.79 & 1781 & 8455 & 8407 & 8361 & 9.5 & 0.81 & 1.03 \\ 4 & \text { YH-5532 } & 0.76 & 0.51 & 1110 & 8468 & 8450 & 8432 & 15.3 & 0.88 & 1.08 \\ 5 & \text { YH-5507 } & 1.15 & 0.59 & 1606 & 10405 & 10374 & 10343 & 13.0 & 0.86 & 1.31 \\ 6 & \text { P-1543 } & 0.57 & 2.14 & 5451 & 7781 & 7288 & 6826 & 2.9 & 0.48 & 0.69 \\ 7 & \text { YH-1898 } & 0.53 & 1.42 & 3005 & 7241 & 7083 & 6929 & 4.8 & 0.66 & 0.78 \\ 8 & \text { DK-6724 } & 0.82 & 0.66 & 1520 & 8792 & 8759 & 8726 & 11.6 & 0.84 & 1.10 \\ 9 & \text { NK-8711 } & 0.56 & 1.47 & 3215 & 7414 & 7237 & 7065 & 4.6 & 0.64 & 0.79\end{array}$

STI: Stress Tolerance Index; SSI: Stress Susceptibility Index; TOL: Stress Tolerance; MP: Mean productivity index; GMP: Geometric mean productivity index; HARM: Harmonic mean productivity index; GOL: Golden mean; YI: Yield index; YSI: Yield stability index

correlation analysis also depicted a strong positive correlation of these indices with kernel yield (Table 2). Another stress index, YSI was found to be positively correlated with kernel yield under high temperature stress conditions $\left(0.270,0.631\right.$ and $\left.0.914^{*}\right)$. However, this correlation was significantly negative under normal conditions $\left(-0.462,-0.685^{*}\right.$ and 0.024$)$. Therefore, YSI is a very valuable index to differentiate heat tolerant hybrids from heat vulnerable hybrids (Mohammadi et al., 2010). Nouri et al. (2011) also reported the usefulness of YSI index for discriminating maize hybrids in selection of highly stable and less susceptible to high temperature stress conditions.
Biplot analysis for the nine screening indices and kernel yield under normal and stress conditions in nine maize bybrids

Three-dimensionalPC1/PC2 biplot graphs were computed between maize hybrids and heat related indices for three sowing seasons to characterize maize hybrids on the basis of kernel yield performance (Figure 3 and 4). In first biplot (Season-2017), which account for $98 \%$ of total variation, four hybrids viz., $\mathrm{YH}-5507$, YH-5427, YH-5482 and DK-6724 were included in the Group A, comprised of highly productive and stable maize hybrids under normal and stress conditions (Figure 3). However, YH-5532 and YH-5213 

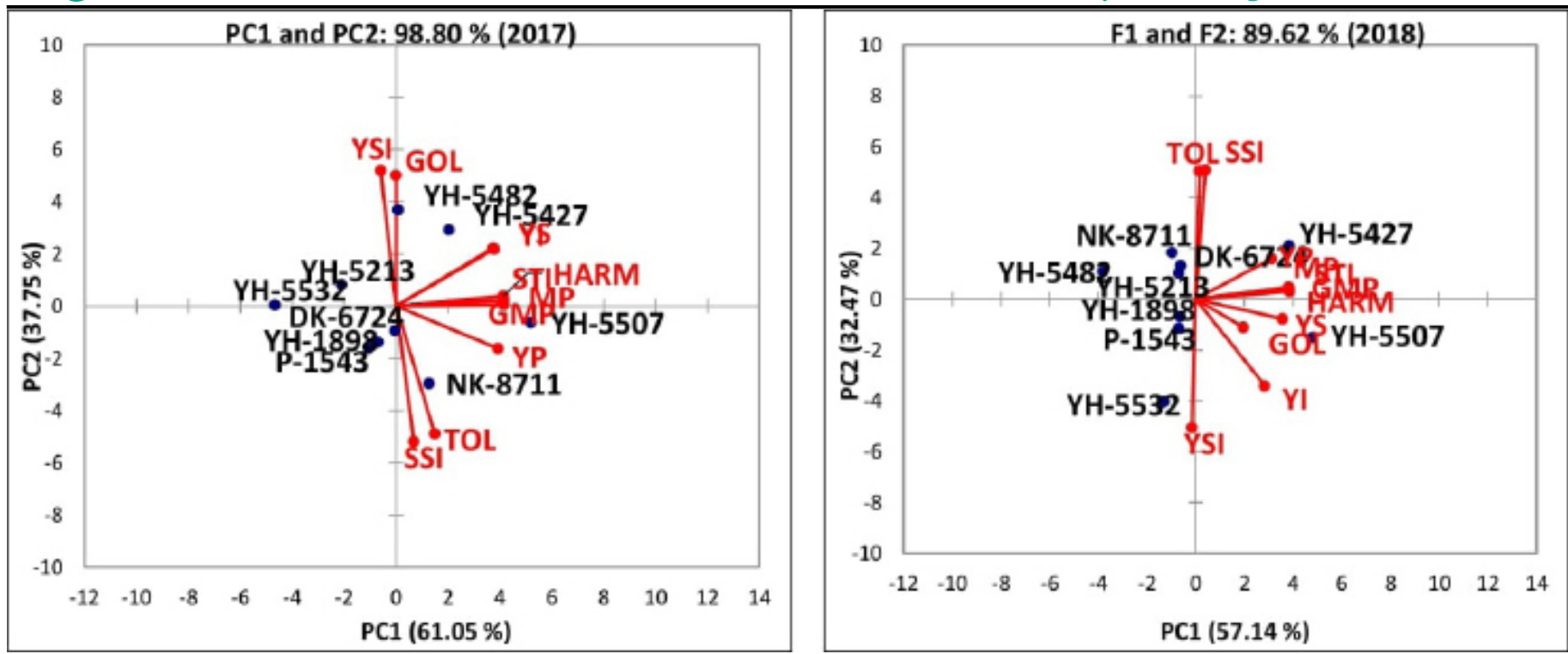

Figure 3: PC-1 and PC-2 biplot of stress tolerance indices for the year 2017 and 2018.

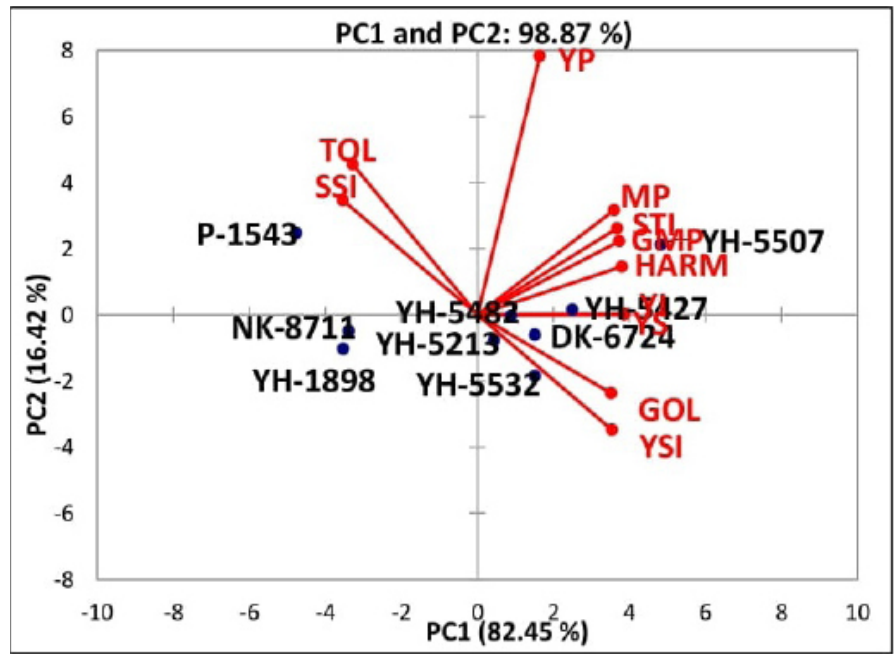

Figure 4: $P C-1$ and $P C-2$ biplot stress tolerance indices for the year 2019.

were included in the Group D due to their poor performance under both conditions. In second biplot (Season-2018), which account for $89 \%$ of total variations, two local maize hybrids $\mathrm{YH}-5507$ and $\mathrm{YH}-$ 5427 showed the highest productivity and stability while $\mathrm{YH}-5532, \mathrm{P}-1543$ and $\mathrm{YH}-1898$ were among the least productive hybrids (Figure 3). Similarly, in the last biplot (Season-2019), which account for 89\% of total variation, again $\mathrm{YH}-5507$ and $\mathrm{YH}-5427$ were the highest yielding, stable hybrids but NK-8711, $\mathrm{YH}-1898$ and $\mathrm{P}-1543$ were the least productive hybrids under normal and stress conditions (Figure 4). Conclusively, $\mathrm{YH}-5507$ and $\mathrm{YH}-5427$ were proved to be the most productive, heat tolerant and stable hybrids under optimal and stress conditions because of having higher PC1 values and lower PC2 values as suggested by Zhao et al. (2019). Similarly, YH-5532, YH-5213 and NK-8711 were the least productive and heat susceptible hybrids under both conditions having lower PC1 and higher PC2 values. Ys had a strong negative correlation with SSI and TOL, as indicated by obtuse angle between their vectors. Many researchers showed a significantly positive correlation between $\mathrm{Y} p$ and $\mathrm{Y} s$, which suggest that high yielding genotypes under optimum conditions are also expected to perform well under high temperature stress (Dorostkar et al., 2015; Grzesiak et al., 2019; Sedri et al., 2019).

\section{Conclusions and Recommendations}

High temperature stress is the key factor in abiotic stresses that significantly reduces maize yield especially in heat prone areas of the World. In any breeding program, which aimed to develop heat resilient maize genotypes/hybrids, selection of parents must be founded upon the stress indices, estimated from kernel yield under optimal and stress conditions. In the current study, results revealed a significantly positive association of $\mathrm{Y} p$ and $\mathrm{Y} s$ with STI, MP, GMP and HARM. Thus, these indices are the most suitable indices for the selection of hybrids having high kernel yield under both normal and high temperature stress conditions. Maize hybrids i.e., YH-5507 and YH-5427 were the highest yielding and heat tolerant hybrids, therefore should be used in varietal improvement programs aimed to develop stress tolerant genotypes for stress affected areas.

\section{Novelty Statement}

This Three-year study is one on its own kind conduct- 
ed in field conditions to check the tolerance of indigenous and exotic maize hybrids in core maize growing area of Pakistan. This research will be very helpful in selecting the maize hybrids for heat prone areas.

\section{Author's Contribution}

\section{MIY, KH, SH, DH, AG, AM, MHB, MAM and}

MA: Got the idea, managed overall article development, collected observed data.

MUK, AM, SAK and MAS: Gave specialized support, facilitated the experimental work provided supervisory help at every phase of research.

MIY, MAM and AM: Organized write-up and performed data analysis as well as offered technical writing assistance.

\section{Conflict of Interest}

The authors have no conflict of interests regarding the publication of this article in Pakistan Journal of $\mathrm{Ag}-$ ricultural Research.

\section{References}

Abu-Romman, S. 2016. Genotypic response to heat stress in durum wheat and the expression of small HSP genes. Rend. Lincei. Sci., 27:261-267. https://doi.org/10.1007/s12210015-0471-9

Aghaei-Sarbarze, R.M., R. Mohammadi, R. Haghparast and R. Rajabi. 2009. Determination of drought tolerant genotypes in bread wheat. Electron. J. Crop Prod., 2:1-23.

Barutcular, C., A.E. Sabagh, O. Konuskan, H. Saneoka and K.M. Yoldash. 2016. Evaluation of maize hybrids to terminal drought stress tolerance by defining drought indices. J. Exp. Biol. Agric. Sci., 4: 610-616. https://doi. org/10.18006/2016.4(Issue6).610.616

Brown, L. 2009. Plan B 4.0: mobilizing to save civilization. W.W. Norton \& Company, New York.

Deryng, D., W.J. Sacks, C.C. Barford and N. Ramankutty. 2011. Simulating the effects of climate and agricultural management practices on global crop yield. Global Biogeochem., CY., 25: GB2006. https://doi. org/10.1029/2009GB003765

Dorostkar, S., A. Dadkhodaie and B. Heidari. 2015. Evaluation of grain yield indices in hexaploid wheat genotypes in response to drought stress. Arch. Agron. Soil Sci., 61: 397-413. https://doi.org/10.1080/03650340.2014.9368 55

Ehlers, J.D. and A.E. Hall. 1998. Heat tolerance of contrasting cowpea lines in short and long days. Field Crops Res., 55 :11-21. https://doi. org/10.1016/S0378-4290(97)00055-5

Fernandez, G.C.J. 1992. Effective selection criteria for assessing stress tolerance. In: Kuo, C.G. (Ed.), Proceedings of the International Symposium on Adaptation of Vegetables and Other Food Crops in Temperature and Water Stress, Publication, Tainan, Taiwan.

Fonseca, E.A and E.M. Westgate. 2005. Relationship between desiccation and viability of maize pollen. Field Crops Res., 94: 114-125. https://doi.org/10.1016/j.fcr.2004.12.001

Ghani, A., M.I. Yousaf, M. Arshad, K. Hussain, S. Hussain, A. Hussain and S. Rehman. 2017.YH1898: A new high yielding, high temperature tolerant local yellow maize (Zea mays L.) hybrid. Int. J. Biol. Biotech., 14 (3): 441-449.

Ghani, A., M.I. Yousaf, M. Arshad, K. Hussain, S. Hussain, D. Hussain, A. Hussain and A. Shehzad. 2020. YH-5427: A highly productive, heat tolerant, stalk rot and lodging resistance, yellow maize hybrid of Punjab, Pakistan. Int. J. Biol. Biotech., 17 (3): 561-570.

Grzesiak, S., N. Hordyńska, P. Szczyrek, M.T. Grzesiak, A. Noga and M. SzechyńskaHebda. 2019. Variation among wheat (Triticum asativum L.) genotypes in response to the drought stress: I-selection approaches. J. Plant Interact., 14: 30-44. https://doi.org/10.1080/1 7429145.2018.1550817

Iqbal, M.A., J. Eitzinger, H. Formayer, A. Hassan and L.K. Heng. 2011. A simulation study for assessing yield optimization and potential for water reduction for summer-sown maize under different climate change scenarios. J. Agric. Sci., 149: 129-143. https://doi.org/10.1017/ S0021859610001243

Kamrani, M., Y. Hoseini and A. Ebadollahi. 2018. Evaluation for heat stress tolerance in durum wheat genotypes using stress tolerance indices. Arch. Agron. Soil Sci., 64: 38-45. https://doi.org/10.1080/03650340.2017.1326 104

Khalid, M.U., N. Akhtar, M. Arshad and M.I. Yousaf. 2020. Characterization of maize inbred lines for grain yield and related traits under heat 
stress conditions. Int. J. Biol. Biotech.,17 (2): 367-375.

Khalili, M., M.R. Naghavi, A.R. PourAboughadareh and S.J. Talebzadeh. 2012. Evaluating of drought stress tolerance based on selection indices in spring canola cultivars (Brassica napus L.). J. Agric. Sci., 4: 78-85. https://doi.org/10.5539/jas.v4n11p78

Khodarahmpour, Z., R. Choukan, M.R. Bihamta and H.E. Majidi. 2011. Determination of the best heat stress tolerance indices in maize (Zea mays L.) inbred lines and hybrids under Khuzestan province conditions. J. Agric. Sci. Technol., 13: 111-121.

Lobell, D.B., M. Bänziger, C. Magorokosho and B. Vivek. 2011. Nonlinear heat effects on African maize as evidenced by historical yield trials. Nat. Clim. Change, 1: 42 - 45. https://doi. org/10.1038/nclimate1043

Mohammadi, R., M. Armion, D. Kahrizi and A. Amri. 2010. Efficiency of screening techniques for evaluating durum wheat genotypes under mild drought conditions. Int. J. Plant Prod 4:1735-8043.

Moradi, H., G.A. Akbari, S.K. Khorasani and H.A. Ramshini. 2012. Evaluation of drought tolerance in corn (Zea mays L.) new hybrids with using stress tolerance indices. Eur. J. Sustain. Dev., 1: 543-543. https://doi.org/10.14207/ ejsd.2012.v1n3p543

Nouri, A., A. Etminan, J.A. Teixeira da Silva and R. Mohammadi. 2011. Assessment of yield, yieldrelated traits and drought tolerance of durum wheat genotypes (Triticum turgidum var. durum Desf.). Aust. J. Crop Sci., 5: 8-16.

Riaz, M.W., L. Yang, M.I. Yousaf, A. Sami, X.D. Mei, L. Shah, S. Rehman, L. Xue, H. Si and C. Ma. 2021. Effects of Heat Stress on Growth, Physiology of Plants, Yield and Grain Quality of Different Spring Wheat (Triticum aestivum L.) Genotypes. Sustainability, 13 (5): 1-18. https://doi.org/10.3390/su13052972

Rosielle, A.A. and J. Hamblin. 1981. Theoretical aspects of selection for yield in stress and non-stress environments. Crop Sci., 21:943-946. https://doi.org/10.2135/ cropsci1981.0011183X002100060033x

Saeed, M., A. Mumtaz, D. Hussain, M. Arshad, M.I. Yousaf, M.S. Ahmad. 2018. Multivariate analysis-based evaluation of maize genotypes under high temperature stress. I3 Biodiversity, 1.
Sánchez, B., A. Rasmussen and J.R. Porter. 2014.

Temperatures and the growth and development of maize and rice: A review. Global Change Biol., 20: 408-417. https://doi.org/10.1111/ gcb.12389

Sedri, M.H., A. Amini and A. Golchin. 2019. Evaluation of Nitrogen Effects on Yield and Drought Tolerance of Rainfed Wheat using Drought Stress Indices. J. Crop Sci. Biotechnol., 22: 235-242. https://doi. org/10.1007/s12892-018-0037-0

Shehzad, A., M.I. Yousaf, A. Ghani, K. Hussain, S. Hussain and M. Arshad. 2019. Genetic analysis and combining ability studies for morphophenological and grain yield traits in spring maize (Zea mays L.). Int. J. Biol. Biotech., 16 (4): 925-931.

Sneath, P.H.A. and R.R. Sokal. 1973. Numerical Taxonomy: The Principles and Practice of Numerical Classification. Free-Man WF and Co., San Francisco, USA

Steel, R.G.D., J.H. Torrie and D.A. Dickey. 1997. Principles and Procedures of Statistics: A Biometrical Approach, $3^{\text {rd }}$ edition. McGraw Hill Book Co., New York.

Tandzi, N. and C. S. Mutengwa. 2020. Estimation of Maize (Zea mays L.) Yield Per Harvest Area: Appropriate Methods. Agronomy. 10(1):29. https://doi.org/10.3390/agronomy10010029

Thornton, P.K., P.G. Jones, G. Alagarswamy, J. Andresen and M. Herrero. 2010. Adapting to climate change, agricultural system and household impacts in East Africa. Agric. Syst., 103: 73 - 82. https://doi.org/10.1016/j. agsy.2009.09.003

Traore, S.B., R.E. Carlson, C.D. Pilcher and M.E. Rice. 2000. Bt and non-Bt maize growth and development as affected by temperature and drought stress. Agron. J., 92: 1027-1035. https://doi.org/10.2134/agronj2000.9251027x

Wahid, A., S. Gelani, M. Ashraf and M.R. Foolad. 2007. Heat tolerance in plants: An overview. Environ. Exp. Bot., 61: 199-223. https://doi. org/10.1016/j.envexpbot.2007.05.011

Yousaf, M.I., K. Hussain, S. Hussain, A. Ghani, A. Shehzad,A.Mumtaz,M.Arshad,A.Mehmood, M.U. Khalid, N. Akhtar and M.H. Bhatti. 2020. Seasonal influence, heat unit accumulation and heat use efficiency in relation to maize grain yield in Pakistan. Maydica, 64(3): 1-9.

Yousaf, M.I., K. Hussain, S. Hussain, A. Ghani, M. 
Arshad, A. Mumtaz and R.A. Hameed. 2018. Characterization of indigenous and exotic maize hybrids for grain yield and quality traits under heat stress. Int. J. Biol. Biotech., 20: 333337. https://doi.org/10.17957/IJAB/15.0493

Yousaf, M.I., K. Hussain, S. Hussain, A. Ghani, M. Arshad, A. Mumtaz and N. Akhter. 2017. Morphometric and phenological characterization of maize (Zea mays L.) germplasm under heat stress. Int. J. Biol. Biotech., 14 (2): 271-278.
Zhang, Y., M.A.R. Mian and J.H. Bouton. 2006. Recent molecular and genomic studies on stress tolerance of forage and turf grasses. Crop Sci., 46: 497-511. https://doi.org/10.2135/ cropsci2004.0572

Zhao, Z., K. He, Z. Feng, Y. Li, L. Chang, X. Zhang, S.Xu, J. Liu and J. Xue. 2019. Evaluation of Yield-Based Low Nitrogen Tolerance Indices for Screening Maize (Zea mays L.) Inbred Lines. Agronomy, 9: 240. https://doi. org/10.3390/agronomy 9050240 